\title{
A Comparative Analysis of China's Association Standards and America's Voluntary Standards
}

\author{
Hui Liu \\ China National Institute of Standardization, \\ Beijing, China \\ Liuhui2604@163.com
}

\begin{abstract}
America's voluntary standards and China's association standards are both the standards developed by the market. But China's association standards are significantly different from established voluntary standards of the US in terms of scale, influence and context where they are. The paper compares China's association standards with American voluntary standards from five perspectives such as development degree of non-profit organizations, government attitude, market demand and overseas experience. The paper believes that the China's government should introduce feasible policy measures in terms of association standards and association standards setting organizations and should refer to and learn the successful experience of American voluntary standards based on a full understanding of advantages, disadvantages and application conditions of American voluntary standard system. In this paper, the author makes a comparison between America's voluntary standards and China's association standards from five dimensions, and obtains the differences between them. Therefore, the paper has some unique characteristics in comparison method.
\end{abstract}

Keywords-association standards; voluntary standards; influencing factors; comparative analysis

\section{INTRODUCTION}

China and the US, as the largest economies in today's world, have different economic development modes and social systems. Similarly, a big difference also exists in standardization management modes of the two countries. American standardization system is a distinct and representative system in the world, which operates very efficiently. At present, development of association standards is an important initiative of China's standardization reform. China refers mainly to the American management of voluntary standards for its reform of association standardization. However, what differences are there between Chinese association standards and American voluntary standards? What can China learn from American voluntary standard system?

Dieter Ernst (2013) deemed that for US proponents, the key to success is a bottom-up, decentralized, informal, market-led approach to standardization [1]. There are significant differences in the organization and governance of standardization processes. These differences reflect the unique characteristics of each country's differing economic institutions, their levels of development, their economic-growth models, and their cultures and history. Andrew Updegrove (2010) believed that to obtain unique benefits, absence of alternatives, support of an existing standard and displacements of a market incumbent are the four important reasons for the foundation of standards consortia [2]. Francis L. (2004) believed that basic skills improved through training, definite positioning, clear common goal and mutual trust based on team interests were the four important factors of high competitiveness of American standard system [3]. Taking China and the US for example, Liu Fei (2009) indicated that the true value of standards lied in good system and strategy based on an analysis of similarities and differences of standardization activities in the two economies [4]. Zhang Shuqing (2007) believed that American bottom-up standards setting mode fully aroused the enthusiasm of all parties concerned in the industry and reflected the principle that standards should reflect technological progress and market demand as soon as possible [5].

\section{OVERVIEW OF ASSOCIATION STANDARDS}

Before the comparative research on China's association standards and American voluntary standards, we have to figure out what standards are. The seemingly simple question has in fact great effects on our understanding of Chinese and American standardization systems.

\section{A. Are standards voluntary or mandatory?}

The most authoritative definition of standards is made by ISO/IEC. ISO/IEC Guide 2:2004 define standards as "documents, established by consensus and approved by recognized bodies, that provide, for common and repeated use, rules, guidelines or characteristics for activities or their results, aimed at the achievement of the optimum degree of order in a given context." The definition has now been accepted and adopted by equation by standardization organizations in most countries, such as BSI, DIN, AFNOR and JISC, etc.

In view of definitions of standards given by ISO, we consider standards essentially voluntary and technically regulatory documents that provide rules, guidelines or characteristics for various activities or results and are for common and repeated use. Voluntariness of standards are mainly reflected in two aspects: one is that standards are made by technical committees participated and composed by different parties on a voluntary basis; the other is that after standards are made, they are selected and adopted by different parties on a voluntary basis. 


\section{B. What are association standards?}

Association standards are actually a general term for standards made by social associations, including institution standards and alliance standards. According to China's national standard GB/T 20004.1-2016 Association StandardizationPart 1: Guidelines for Good Practice, association standards refer to standards self-government made and released and voluntarily adopted by associations according to their own standards setting procedures. In this definition, there are two terms to be further defined: associations and standards. According to the interpretation of the standard, associations mean social organizations with corporate capacity, corresponding professional expertise, standardization ability as well as organization and management ability, such as societies, institutions, chambers of commerce, federations and industrial technology alliances. The definition of standards in GB/T 20000.1-2014 is adopted.

\section{Motives of association standardization}

Before studying association standards, we have to first of all identify why there are association standardization and why social organizations set association standards. In China, the setting of association standards is remarkably different from setting of national, industrial and provincial standards. National, industrial and provincial standards are made by the government consist of recommendation and mandatory standards, while setting of association standards is now a bottom-up spontaneous market behavior. Association standardization is implemented with two motives. Firstly, it aims at regulating enterprise production and strengthening industry self-discipline. Alliance standards are set to regulate enterprise production, eliminate production without standards and guide healthy and orderly development of enterprises or clusters. In many industries or industrial clusters in China, especially enterprises or industrial clusters featured by low technical content in products, small scale and weak innovation ability, alliance standards are set for this purpose. These standards are the most typical in Pearl River Delta and Yangtze River Delta in China.

Another motive of association standardization is to give rapid response to technological change in a certain field and achieve competitive advantage in technology application. Take alliance standards in ICT industry for example. ICT industry constantly sees emergence of new technologies, products and services, but since current standards setting organizations have no technical capacity of setting new standards, the demand of rapid technological development cannot be satisfied. In this case, technologically leading enterprises or enterprise groups have increased market share of products and relevant technologies through market exploitation until they occupy main market and their technical standards become de facto standards, and then promoted the application of these standards by establishing patent alliances[6].

\section{Relationship between voluntary standards and association standards}

The concept of voluntary standards is relative to mandatory standards. Standards are specified by TBT agreements as voluntary, so the term of voluntary standard occurs. "Voluntary" means voluntary participation in standards setting and voluntary adoption. Standard systems of most countries in the world are voluntary. With the US as an example, in American standard system, not only institution standards and alliance standards are voluntary, but most of America's national standards are voluntary. This indicates that association standards are, but do not completely cover, voluntary standards, since most national standards are voluntary. Therefore, the concept of association standards is defined mainly based on applicability of standards, which are limited within associations or alliances. Actually, comparison of the two can only be made through whether standards are voluntary or mandatory; with respect to range of application of standards, voluntary standards can be applied throughout a country, an industry, an association or alliance, and even an enterprise.

\section{STATE OF THE ART OF CHINESE AND AMERICAN ASSOCIATION AND VOLUNTARY STANDARDS}

\section{A. State of the art of Chinese association standards}

1) Types of association standards setting and choosing

Since the 1980s-1990s, some social associations and industrial alliances in China have begun to set market-required standards on their own, thus a new type of standards beyond the current standard system1, i.e., association standards, has emerged. China's association standards may be set by two types of organizations: one is public societies and associations and the other is alliances. At present, social organizations undertaking standardization work in China are mostly industry associations or government-run NGOs. Chinese alliance organizations can be divided into at least two categories: one is non-governmental non-profit associations (e.g., CSA); the other is interest groups of a few enterprises (e.g., ODCC), equivalent to consortia founded by a few highly-competitive enterprises. China's association standards mainly include institution standards and alliance standards. Though association standards have not been included in the current standard system or provided with administrative enforcement mechanism, these standards develop with strong momentum, involve an increasing number of sectors and constantly expand in terms of territorial scope, with more and more being effectively executed.

\section{2) Characteristics of association standardization} development

From the perspective of industry, China has now a huge number of social associations registered with Ministry of Civil Affairs, which involve extensive categories and natures, including industry-oriented and comprehensive associations, such as China Machinery Industry Federation and China National Light Industry Council; professional associations geared to a specific industry and serving production and management enterprises of a category of products, such as China Automotive Industry Association and China Household Electrical Appliances Association; and associations of other natures, such as standardization associations, art associations, quality associations, safety and health associations. At present, some of these social associations have set institution standards for their own industries or relevant industries, for instance, engineering construction industry, household appliance 
industry, food industry, pharmaceutical industry and metallurgical industry.

From the perspective of region, China's association standards have developed mainly from alliance standards. They originate from economically developed Pearl River Delta and Yangtze River Delta and have gradually expanded nationwide.

In 2015, SAC launched pilot association standardization nationwide. 39 units such as Chinese Institute of Electronics and China Association of Chinese Medicine, as the first batch of pilot units, carried out the pilot work. At present, National Information Platform for Association Standards has been set up, where 225 association organizations have registered to carry out association standardization work.

\section{B. State of the art of American voluntary standards}

Unlike other countries, standards setting organizations in the US first appeared in private sectors and standards setting aimed at satisfying special requirements of these sectors and solving problems in production and engineering. Early pioneers of the standardization in the US are science and technology societies (e.g., American Society of Civil Engineers (ASCE) founded in 1852, American Society of Mechanical Engineers (ASME) founded in 1880 and American Society for Testing and Materials (ASTM) founded in 1898) and trade associations (e.g., American Iron and Steel Institute (AISI) founded in 1855). From the very beginning, these societies and institutes have the right to set their standards.

American voluntary standard system consists mainly of American national standards, society (institution) standards and alliance standards. Voluntary standards are featured by voluntary participation in standards setting and voluntary application. American society (institution) standards are set by various society (institution) organizations, all producers, users and consumers that are interested and representatives of the government and the academia through consultation procedures, and suitable for respective industries (professions). Alliances, unlike societies (institutions), are committed mainly to rapidly setting alliance standards that can reflect the latest technology in respective industries and are formed by multiple voluntary enterprises to obtain common interests, and alliance standards are normative documents set by alliance members within respective alliances upon consultation to satisfy their own needs.

American voluntary standards are set mainly by nongovernmental organizations. These non-governmental organizations (mostly industry associations and academic organizations) that exert their own professional advantages within the scope of respective professions or industries can set and release standards regarding their own professions or industries, and approve release of institution standards with respective serial numbers. Therefore, American standards are decentralized and diversified. American National Standards Institute (ANSI) is the management and coordination agency for American voluntary standard system, which doesn't set standards, but accepts basic standards of national influence among standards set by non-governmental organizations as national standards, and grants each of them an ANSI code.
Thus, American national and institution standards are set mainly by non-governmental organizations.

\section{COMPARATIVE ANALYSIS ON THE INFLUENCE FACTORS OF THE DEVELOPMENT LEVEL OF CHINESE AND AMERICAN ASSOCIATION STANDARDS}

At present, there is no special research on the influence factors of the development of association standards. Only two general factors influence how things develop, i.e. internal and external factors. The interaction between internal and external factors determines the direction and path of the development and change of things. The development of association standards is also affected by the internal and external factors. The internal influence factors of the development of association standards include the development degree of the non-profit organizations and the standardization ability of the association standardization organizations. The external influence factors include government's attitude, market demand and foreign related experience. In this part, we will carry out a comparative analysis of above-mentioned five factors influencing the development of Chinese and American association standards.

\section{A. Development degree of non-profit organizations}

The non-profit organization is the foundation and organization guarantee for the association standardization organization and its development degree determines the development level of the association standardization organization. The full development of non-profit organizations in a country or a region may directly affect the development level of the association standardization organization.

China lags behind the United States in terms of the development degree of non-governmental organizations which is mainly manifested in two aspects. One is the quantity. There are still less standardization organizations established by the private groups because the association standardization has just started in China. At present, the vast majority of 225 associations registered in the national association standard information platform are under the background of the government. In the United States, there are 295 ASDs (Accredited Standards Developers) accepted by ANSI which are mainly self-government bodies. Throughout the United States, there are more than 700 SSOs (Standard Setting Organizations). The other is the development of history. Most of China's association standardization organization was established after 1978 when the reform and opening up started and only a few of the institutes and the associations were established before the reform and opening up and even the establishment of new China in 1949. For example, the Chinese Hydraulic Engineering Society, formerly known as Chinese Institute of Hydraulic Engineering, was founded in 1931 and renamed in 1957. The Chinese Society of Electrical Engineering, formerly known as Chinese Institute of Electrical Engineers, was founded in 1934 and renamed in 1958. The Chinese Mechanical Engineering Society was founded in 1936. While many U.S. associations have longer history than those of China, such as ASTM, ASME, UL and so on, which were established in the late nineteenth Century. 


\section{divints}

Moreover, another significant difference between the nonprofit organizations of both China and the United States is that China's existing non-profit organizations include many institutes, associations, chambers of commerce, unions and industrial technology alliances under the background of the government. As these organizations associated with the government reform are, to a certain extent, products of the government reform and government function socialization, their main social resources including personnel, financial, material, information, management and organization resources are mainly from government agencies under the monopoly of power control and thus these organizations are of administrative nature or top-down bureaucrat simulated the government [7].

\section{B. Standardization ability of non-profit organizations}

The standardization ability of non-profit organizations is another important internal factor affecting the development level of association standardization. The standardization ability level of non-profit organizations is affected by organization scale, organization income, R\&D input, personnel quality, intellectual property status and other factors. China's national institutes, associations, chambers of commerce, unions and industrial technology alliances under the background of the government have a high level of standardization because these organizations are easy to get resources for standardization activities from the government, including funds, personnel and policies, etc.. For example, China Communications Standards Association (CCSA) established under the promotion of the government can obtain many resources under the control of the government and is commissioned by the relevant departments to develop the national standards for communication technology and industry standards, and CCSA can also get subsidies for the standardization from the government. Since its establishment in 2002, CCSA has developed 367 national standards and 3,022 industrial standards which cover various traditional and new areas of communications. However, China is still in the absence of consortia composed of a small number of large enterprises like the United States, which also reflects that Chinese enterprises lack in technology research and development and innovation capacity of in the field of related industries and have a larger gap compared with the United States.

In the United States, many association standardization organizations have high authority, such as ASTM, ASME and IEEE, and standards set by these standardization organizations are widely used in the world and have enjoyed a high reputation in the field of standardization and industry in China, and its influence even greater than ISO standard. Many of the Chinese industrial exports to the United States are in compliance with the standards set by these organizations [8]. In addition to such professional standardization bodies, the corporate interest groups formed by top and large enterprises in the United States, i.e. consortia, also has a strong ability of standardization in the relevant fields, especially in the ICT field, such as W3C (World Wide Web Consortium) and IETF (Internet Engineering Task Force) which represent the highest innovation capability of technology development today.

\section{Government Attitude}

The Chinese government is supporting and encouraging the development of association standards. At present, the Chinese government is supporting the development of the association standards by laws and policies. In laws, the new amendment to the standardization law (revised draft) makes the provisions of the association standards for the first time, i.e. "social organizations established lawfully can set association standards. The association standards setting shall be standardized, guided and supervised by the competent administrative department of standardization under the State Council.” This is one of the highlights in the amendment to the standardization law, marking a clear legal status of the association standards in China's standard system. In terms of policy, the relevant documents issued by the Chinese government, such as Deepening Standardization Reform Scheme, Guiding Opinions on the Cultivation and Development of Association Standardization, clearly support the development of association standards.

The laws of the United States protect and promote the operation and development of voluntary standards from many aspects. The National Technology Transfer and Advancement Act (NTTAA) approved by The United States Congress in February 1996 require federal agencies to minimize the specialized standards for the government and to use voluntary standards as far as possible. To ensure the effective implementation of NTTAA, enabling voluntary standards adoptable as a basic policy for a long term, shortly after the release of the NTTAA, the Office of Management and Budget (OMB) issued the Circular No. A-119 -- Federal Register (Federal Participation in the Development and Use of Voluntary Consensus Standards and in Conformity Assessment Activities) (hereinafter referred to as Circular No. A-119) to match NTTAA, and revised it in 1998. Circular No. A-119 is a supplementary document to ensure the implementation of the NTTAA. In August 2004, the United States issued the Standards Setting Organizations Promotion Act which mainly protects the rights of the voluntary standards setting organizations and is designed to encourage the standards setting organizations to develop standards. In addition, the United States Congress passed The Telecommunications Act and The U.S. Consumer Product Safety Act to put forward specific requirements for the federal government to adopt voluntary standards.

It can be found from the comparison between the support of China and the United States to the association standards that the United States gives strong and comprehensive support to voluntary standards in both laws and systems. In contrast, China has just released a few encouraging policies and indefinite incentives for association standards due to immature development of association standard, supporting the association standards from the macro and without specific operational instruction. In China, association standards are not referred by the laws, regulations and standards set by the government. There are few government officials to participate in the standardization activities of non-governmental organizations and to give support to the association standards. 


\section{Market demand}

In China, tremendous market demands speed up association standards development. Taking China Solid State Lighting Alliance (CAS) standard as examples, CAS was founded in Oct. 2004 by 46 domestic backbone enterprises, universities and research institutions in semi-conductor lighting industry on the principle of "voluntary, equality and cooperation", and now boasts more than 530 members, with the industrial output value accounting for over $70 \%$ of China's total in the field, of which there are more than 20 listed enterprises, including the Top 4 traditional lighting enterprises, the institutions in China of the internationally Top 5 enterprises, Top 5 Taiwan enterprises and Top 10 testing institutions of China, etc. In 2015, China semiconductor lighting industry reported the entire scale up to 424.5 billion yuan. Over the past 10 plus years, China has gradually narrowed its gap with the international level in semi-conductor lighting sector, the industry has developed initial scale and the industrial chain has kept improving. However, LED lighting field features low access threshold and simple assembly, leading to highly different product quality levels and wide gap of product prices, for example, selling prices of bulbs of the same type vary from 5 yuan to 50 yuan. Main reasons for such market disorder and product quality difference are incomplete standard, testing and certification systems at the initial period of emerging industry development. Rapid development of LED industry has made it urgent to formulate relevant product standards and technical specifications, but existing technical committee and industrial standard setting department are established on the basis of traditional lighting and administered by different departments, unable to respond to the development of emerging application fields in time. Meanwhile, existing standard setting procedures are slow relatively, unable to quickly reflect current situations of market demand and industrial development, so a new standardization mechanism is urgently needed to meet the needs of rapid development of emerging industries. Now semi-conductor lighting has entered functional lighting field such as road lighting, but it will be some period before relevant national standard is released as the technology is less mature at present and no ready testing method and standard are available for reference both at home and abroad. Therefore, the industry urgently needs relevant measures to be released, so as to guarantee LED functional lighting product development and deep progress of energysaving application demonstration. To this end, CSA took the first to advance LED streetlight standardization and released the Alliance's first technical specifications Integrated LED Streetlight Measurement Method in 2008. Some technical provisions in the standard have been recognized and adopted by the Energy Star Standard of The United States Department of Energy. By far, The Alliance has formulated 36 standards covering LED product performance, measurement method, driving power supply and application interface, etc. [9].

The standardization in the U.S. was firstly driven by the needs of technical compatibility, voluntary standard setting organizations initially emerged in private departments for solving their problems in production, and industrial associations formulated technical standards of their own fields respectively. With science and technology developing, particularly the life cycle of technologies and products in ICT field became shorter and shorter, technology innovation and change speed became greatly faster than that traditional organization setting of standards. Enterprises in such fields with technology developing quickly began to realize the importance of setting new technical specifications as early as possible to develop new market. However, if completely following official standard setting procedures and channels, it would be an obviously too long process and time for standard formation. Single enterprise, due to limitations in scale, etc, is hard to completely control market and unable to control standard by itself. In such a situation, enterprises enjoying common market interest need to compromise each other and finally form an association to jointly formulate association standards, so as to meet demands of quickly changing technologies and industries.

\section{E. Foreign experiences}

Developing countries, limited to their abilities and experiences, always attach high importance to successful experiences and practices of developed countries in developing economy, which is also a common approach adopted by many developing countries in the course of development. We call such influences of foreign successful experiences on developing countries as benchmarking. Benchmark management not only is an effective approach common in business management, but has become a systematic tool to continuously improve competitiveness in many countries with government departments valuing the international competitiveness of their industries, enterprises and countries [10]. Association standards have experienced a development history of over 100 years in the U.S., become very mature and achieved good economic and social benefits, which is undoubtedly very attractive to China who wants to develop association standards.

At present, there are two major standardization management modes internationally, namely U.S. Mode and EU Mode. The U.S. decentralized self-government voluntary standard management mode is different from EU and other countries internationally, and a unique one. Such management mode is closely tied with the U.S. economic system, development level, economic growth mode, history and culture. In China's economic field reform and opening-up, many practices have drawn on the experiences of Western developed countries. In terms of standardization, an important reference for China's standardization reform, particularly association standards reform, is the U.S. Government experiences in voluntary standard, while the compulsory standard reform mainly refers to EU's technical regulations management mode.

\section{HOW CAN THE CHINESE GOVERNMENT PROMOTE DEVELOPMENT OF ASSOCIATION STANDARDIZATION}

\section{A. How does China develop association standards?}

In the current newly-revised Standardization Law, association standards have been included into the national standard system, and relevant policy documents have been released to encourage development of association standards, which are greatly significant for promoting development of association standards in China. But the above-mentioned measures are not enough alone, and further specific policy 
measures must be formulated to promote development of association standards:

1) To provide non-governmental standardization organizations a loose development environment

Non-governmental standardization associations, alliances and other organizations are major power to drive development of association standards in China. China's reform of non-profit institution administration should lower the threshold against private enterprises' efforts in jointly establishing non-profit institutions, particularly should ease the limitation on establishment of standardization industry associations by nongovernmental parties, so as to create a good legal environment for promoting creation and healthy development of nongovernmental standardization groups. The government should withdraw from the administration of industrial recommendatory standards, and completely leave the setting of product standards for industrial needs to association standardization.

2) Association standardization organization should open up wider to foreign enterprises and institutions

At present, some association standardization organizations in China, such as partial industrial associations and alliance organizations have the participation of foreign companies. For example, China Communications Standards Association (CCSA) has foreign observers, who are entitled to participate in CCSA's business meeting, including members conference and activities; to submit texts in their branches and technical committee; to get phasic work documents and officiallypublished standard text, etc.; to acquire the Association's public journals and technical information, etc.; to criticize, make proposal for and supervise the Association's work. Some American enterprises such as Intel, Qualcomm, IBM, Apple, Oracle and Cisco, etc. have participated in CCSA's standard setting activities as CCSA's observers. But China's alliance organizations have not opened up enough to foreign enterprises. In order to increase association standardization organizations' standardization level and influence, the limitations on foreign enterprises and institutions should be further loosened in the future, to allow more foreign enterprises and institutions to become official members and to participate in domestic association standardization activities.

3) To encourage citing association standards in laws and regulations

When involving specific technical requirements in making laws and regulations, relevant institutions should consider whether there are current association standards applicable. If yes, such standards can be cited, and relevant contents of such standards can be included in the laws and regulations; if not, the regulations authorities can entrust the standard institutions accepted by them with setting corresponding standards (the regulations authorities should dispatched their representatives to participate in the setting, so as to ensure their opinions able to be reflected in the standards), and then cited the standards formulated in relevant technical regulations. Such practice citing association standards in laws and regulations will greatly lift positions of association standards and promote association standards development.
4) To expand scope of association standards setting step by step

The Chinese Government should gradually cancel such provisions in the Guiding Opinions that "social organizations can develop association standards if no corresponding national standard, industrial standard and local standard are available, so as to quickly respond to the demands of innovation and market for standards and fill in the gap of existing standards." Social organizations can develop association standards in the fields with relevant national standard, industrial standard and local standard available. Existing industrial standards can be partially transformed into national standard series, or into existing social organizations for management if unable to be changed into national standard system. China's certification and accreditation systems and testing institutions should thoroughly change their current practice that does not recognize association standards.

\section{B. What will be China's mode to develop association standardization in the future?}

The mode for China to develop association standardization should be of government guiding, social organization leading and technical organization supporting.

\section{1) Government guiding}

Government departments should play the role of guiding and coordination in the process of social association standards development. Government departments can map out guiding opinions on social association standards development to stipulate aspects of social association standards setting and revision and registration for reference, etc; can formulate the code of good practice for social association standardization and take advantage of third-party evaluation and credibility mechanism to enhance guidance to social association standardization activities; can take social association standardization pilot and demonstration measures to advance works of social association standardization; can establish corresponding incentive mechanism to encourage enterprises' participation in formulating and credibly implementing social association standards.

\section{2) Social organization leading}

Industrial associations and other social organizations are important ties for communication and contact between governments, enterprises and relevant technical institutions, can transmit government policies to enterprises and express to government enterprises' demands; can coordinate relations and interest of all related enterprises and organize research institutions, testing institutions and enterprises, etc. to jointly carry out works. Therefore, industrial associations and other social organizations are core forces to organize setting of social association standards and major parties in the responsibility for social association standards, and should play a leading role in setting and implementation of social association standards.

\section{3) Technical organization supporting}

Colleges and universities, research institutions and testing institutions are equipped with the advantages of advanced test equipment, abundant testing resources and being familiar with products and understanding trends of development of the whole industry, so they should actively participate in the setting of 
social association standards, to ensure setting of social organization standard with advanced technical indicators and high operability. The technical institutions for standardization should also strictly follow national laws and regulations and requirements of compulsory standards to properly carry out control of quality of social association standards, and provide enterprises with technical standard consulting service.

\section{How should China learn from and draw on the experience of American voluntary standard system?}

1) To sufficiently recognize strong points and weak points and the foundation of application of American voluntary standard system.

Formation of American voluntary standard system is nourished by its solid economic and technical levels, marketization ability and cultural tradition advocating freedom and democracy. The market-oriented decentralized selfgovernment voluntary standard system satisfactorily reflects demands of different stakeholders, and is an important source for the U.S. to successfully realize industrial innovation, but with problems itself naturally. Therefore, when advancing the reform of standardization system in an all-round manner today, we need to get a clear understanding of the following points while drawing on the experiences of American standard system:

First, completely copying American standard system means obvious limitation. A country's national economic system, development level, economic growth mode and uniqueness of history and culture will influence its standard system. Facing similar tasks of standardization, countries notably differ from each other in standardization process. Therefore, the practice of completely copying American standard system has clear limitation. Second, we should attach full importance to the role of non-governmental standardization organizations, particularly rely on societies (associations) and other social organizations to step by step establish the standard setting system with enterprises as major players and associations as the core, and form a self-discipline and orderly standardization operation mechanism suitable for market economy development. Third, we should lay stress on government's role of supervision and coordination. In American voluntary standard system, the government's role is too weak, causing more conflicts and lack of effective coordination of all stakeholders, which has become a limitation on an effective, open standardization process. Therefore, China should, on the one hand, give play to the decisive role of market in allocating standardization resources, and on the other hand, pay close attentions to the government's role of macro administration and coordination in establishing equality competition environment and providing public services for standardization and other aspects.

2) To scientifically balance the influence of IPRs system on association standards

The differences between developed countries and developing countries in legal system, jurisdiction authority, technology progress mode and culture, etc. have caused longterm unbalanced development of IPRs systems between the South and the North in the world. Strict IPRs system ensures developed countries' position in transforming their absolute advantages in technology into economic interests, and to solidify their monopoly in global hi-tech field; while developing countries, limited to their relatively backward knowledge accumulation and R\&D ability, always resort to relatively loose, moderate IPRs protection mechanism, so as to make full use of international spreading and transfer of knowledge and technology to advance leap-forward development of their industrial technologies. Therefore, developing countries are not necessary to implement protection of IPRs to such an extent as developed countries execute. The optimal IPRs protection intensity suitable for developed countries is higher than developing countries, and overprotection of IPRs will hinder developing countries' technological development course [11]. IPRs protection can promote a country's technology innovation under certain conditions, but too strong IPRs protection will reduce technology innovation rate, therefore there exists an optimal range of IPRs protection. The design of IPRs system should give considerations to the following aspects: on the one hand, IPRs protection intensity cannot be too low, so as to ensure knowledge "exclusiveness" and return on innovation, to make researchers and developers have the power to carry out technology innovation; on the other hand, IPRs protection intensity cannot be too high, so as to guarantee that any property right protection will not go to such an extent to vest patent owners with too dominating monopoly, which will cause market distortion and out-of-balance resources allocation.

\section{ACKNOWLEDGMENT}

This research was supported by the President Foundation of CNIS (572016Y-4676).

\section{REFERENCES}

[1] Dieter Ernst. (2013). America's Voluntary Standards System: A Best Practice Model for Asian Innovation Policies?. East-West Center Policy Studies Series.

[2] Andrew Updegrove.(2010). When and How to Launch a Standards Consortium. http://www.consortiuminfo.org/bulletins/sep10.php\#feature.

[3] Francis L. (2004). On Four Major Elements of Competitiveness from American Standard System. Shanghai Standardization Monthly.(7):1517.

[4] Liu Fei. (2009). The Value of Standard is Rooted in System and Strategy: Comparison of Standardization Systems and Strategies Between China and the U.S. Communications Standardization. (11):20-22.(In Chinese)

[5] Zhang Shuqing. (2007). American National Standard Management System and the Operation Mechanism. World Standardization \& Quality Management, (10):17-19. (In Chinese)

[6] Yao Yuan, Song Wei. (2010). Comparative study on the formation pattern of patent pools under the trend of patent standardization-DVD mode vs MPEG mode. Studies in Science of Science, 28(11):1683-1690. (In Chinese)

[7] Wang Ming, Jia Xijin. (2003). China’s Non-profit Organization: Definition, Development and Policy Suggestions, collected in Party III NGO and China, Social Transition and Non-governmental Organizations under Globalization compiled .Fan Lizhu, Shanghai People’s Publishing House.263-264(In Chinese)

[8] Wang Ping, Liang Zheng. (2013). Discussion on Standards Alliances or Consortia. China Standardization, (5):51-54(In Chinese)

[9] Wang Ping, Liang Zheng. 2016. “Current Situations of China's Nonprofit Standardization Organization Development: Case Study Based on Organization Characteristics.” China Standardization. (10)100-110(In Chinese) 
[10] Kong Jie, Cheng Zhaihua. (2004). Review of Benchmark Management Theory. Journal of Dongbei University of Finance and Economics, (2):37.
[11] Wang Hua. (2011). Is More Stern IPRs Protection System Favorable for Technology Innovation? Economic Research Journal, (2): 124-135. (In Chinese) 